\title{
2 次元磁気特性を用いた永久磁石モータの鉄損解析
}

\author{
Iron Loss Analysis of Permanent Magnet Motors Taking Account \\ of Two-Dimensional Magnetic Characteristics
}

\author{
下地広泰・榎園正人・戸高孝・桘田雄二・高橋秀一 \\ 大分大学工学部、大分市旦野原 700 番地 \\ H.Shimoji, M.Enokizono, T,Todaka, \\ Y.Tsuchida, and S.Tkahashi \\ Faculty of Engineering, Oita Unversity, 700 Dannoharu, Oita, Japan \\ (2000年 10 月 10 日受理、2001年1月 24 日採録)
}

Iron loss analysis of a permanent magnet motor was carried out taking account of the anisotropy of the magnetic material. Recently, it has become possible to measure magnetic material in terms of a vector quantity, as a result of improvements in measuring technique. Since the non-oriented silicon steel sheets used as the iron core material are anisotropic, it was necessary to carry out the analysis in such a way as to take account of the anisotropy of the magnetic material. We were able to do this by combining the finite element method with the Enokizono \& Soda (E\&S) modeling.

Key words: the permanent magnet motor, finite element method, E\&S modeling, iron loss analysis, two-dimensional magnetic measurement

\section{1. はじめに}

近年様々な磁性材料が開発されている。しかしながら従 来の磁性材料よりも複雑な特性を示すため実際の機器に導 入した際、目的の性能を引き出せないといった問題点が明 らかになってきている。そのため材料特性をいかに把握し て設計できるかが大きなポイントとなる。我々はこの複雑 な磁気特性を把握するため測定においては 2 次元磁気特性 装置を用いた測定を行っている。また、磁界解析において は E\&S モデリングと有限要素法を組み合わせることにより、 大きさのみならず空間的な角度の非線形性を考虑した磁界 解析を可能とし、磁束密度 $\mathrm{B}$ と磁界強度 $\mathrm{H}$ をべクトル量と して扱えるため直接鉄損計算も可能となっている。本論文 ではステータコアに無方向性ケイ素鎆板を用いた分割コア 永久磁石モータの磁界解析を行っている。近年分割コアを 用いたモータが注目されている。分割コアは各ティースに 巻き線を施せるため、導線の占有率向上のため銅損が軽減 できる。また、磁性材料の容易軸方向を考虑した設計が可 能となる。しかしながら磁界解析においてはこのような材 料特性を考虑することは難しく現在は経験と勘を頼りに設 計している。そこで、本手法を用いることにより鉄損軽減 を目的に容易軸方向の最適化を可能にしている。従来まで の磁界解析では複雑な材料特性を考虑することはできなか ったため容易軸方向による違いは確認できなかった。本論
文では分割コアごとに圧延容易軸方向を最適化することに よって鉄損の軽減が可能なことを示す。このことにより安 価な材料でもさらなる低鉄損化が可能であり、従来機の大 幅な形状変更を行わなくても同じコストで高効率化をはか ることが可能である。

\section{2 次元磁妸测定装置の骤要}

\section{12 次元磁新测定装相}

Fig. 1 に2 次元磁気測定装置の概要図を示す。X方向とY方向 にヨークを配置し、試料に磁束を集中させるため先端を 45 度に 加工し、試料に任意の波形を励磁できるようになっている。試料 とヨークの間には $0.1 \mathrm{~mm}$ のギャップを施している。

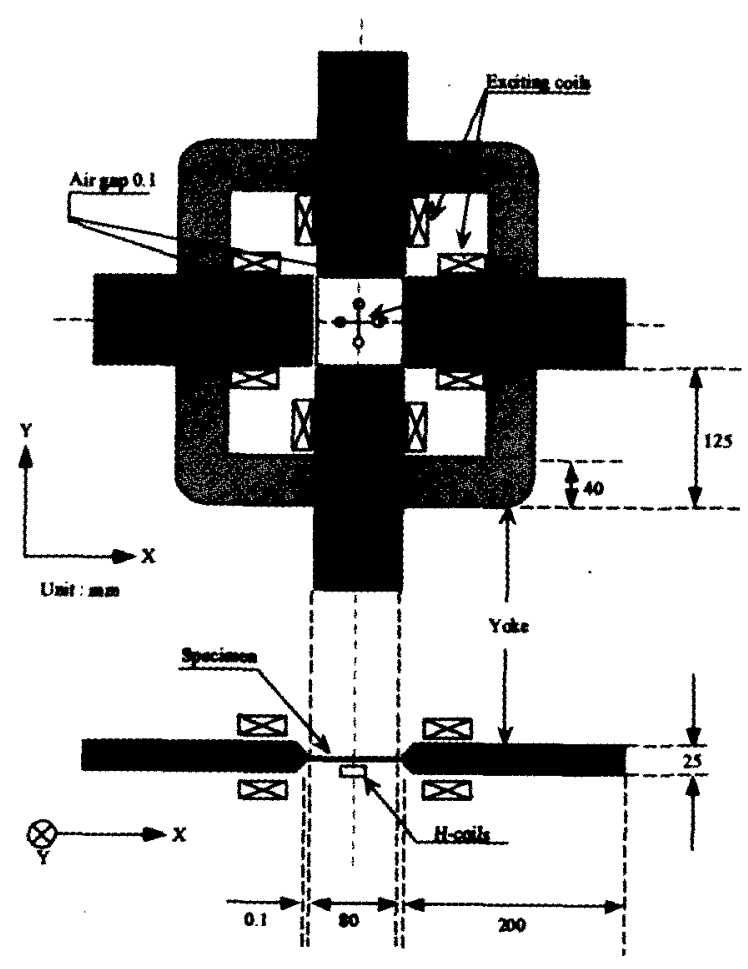

Fig. 1. Two-dimensional magnetic measurement apparatus. 


\section{2 磁性材料の非䗷形性}

Fig. 2 にそれぞれの磁束条件を定義する。回䡩磁束条件は容易 軸方向と最大磁束密度の角度を表す $\phi 、$ 棈円の膨らみを表す軸比

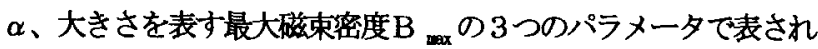
る。交番磁束は軸比 $\alpha$ がゼロとなる。

次に Fig. 3〜5 はそれぞれ無方向性ケイ素銅板、一方向性ケイ 素銅板、二方向性ケイ素銅板の測定結果である。それぞれの磁束 密度条件は同じであるにもか加わらず磁界においいては全く違った 特性を示している。磁束密度条件は軸比 1 、最大磁束密度 $1[\mathrm{~T}]$ 、 である。注目すべきは無方向性ケイ素銅板においても困難軸方向 と容易軸方向が存在することである。これらの結果から磁界解析 において大きさのみでは不十分で方向と大きさの非線形性を考慮 することが必要であることがわかる。

\section{E\&S モデリングと定式化 ${ }^{[3]}$}

\section{1 ERS モデリング}

まず、実䤅データから以下の式のようにフーリエ変换を用いて近 似与る。磁束密度は完全な正弦波形に制御されている。 $A 、 B$ は それぞれフーリエ変換から求められる保数である.

$$
\begin{aligned}
& \left\{\begin{array}{l}
B_{x}=A_{B_{x} 1} \cos \omega t-B_{B_{x} 1} \sin \omega t \\
B_{y}=A_{B_{y} 1} \cos \omega t-B_{B_{y} 1} \sin \omega t
\end{array}\right. \\
& \left\{\begin{array}{l}
\frac{\partial B_{x}}{\partial \theta}=-\omega A_{B_{x} 1} \sin \omega t-\omega B_{B_{x} 1} \cos \omega t \\
\frac{\partial B_{y}}{\partial \theta}=-\omega A_{B_{y} 1} \sin \omega t-\omega B_{B_{y} 1} \cos \omega t
\end{array}\right. \\
& \left\{\begin{array}{l}
H_{x}=A_{H_{x} 1} \cos \omega t-B_{H_{x} 1} \sin \omega t+A_{H_{x} 3} \cos \omega t-B_{H_{x} 3} \sin \omega t \\
H_{y}=A_{H_{y} 1} \cos \omega t-B_{H_{y} 1} \sin \omega t+A_{H_{y} 3} \cos \omega t-B_{H_{y} 3} \sin \omega t
\end{array}\right.
\end{aligned}
$$

E\&S モデリングは以下の式のように表されるため

$$
\left\{\begin{array}{l}
H_{x}=v_{x p} B_{x}+v_{x t} \frac{\partial B_{x}}{\partial \theta} \\
H_{y}=v_{y r} B_{y}+v_{y y} \frac{\partial B_{y}}{\partial \theta}
\end{array}\right.
$$

結局それぞれのvは以下のように求められる。

$$
\left\{\begin{array}{l}
v_{x r}=k_{x r 1}+k_{x r 2} B_{x}+k_{x r 3} B_{x}\left(\frac{\partial B_{x}}{\partial \theta}\right)+k_{x r 4}\left(\frac{\partial B_{x}}{\partial \theta}\right)^{2} \\
v_{x i}=k_{x i 1}+k_{x i 2} B_{x}+k_{x i 3} B_{x}\left(\frac{\partial B_{x}}{\partial \theta}\right)+k_{x i 4}\left(\frac{\partial B_{x}}{\partial \theta}\right)^{2} \\
v_{y r}=k_{y r 1}+k_{y r 2} B_{y}+k_{y r 3} B_{y}\left(\frac{\partial B_{y}}{\partial \theta}\right)+k_{y r 4}\left(\frac{\partial B_{y}}{\partial \theta}\right)^{2} \\
v_{y i}=k_{y i 1}+k_{y i 2} B_{y}+k_{y i 3} B_{y}\left(\frac{\partial B_{y}}{\partial \theta}\right)+k_{y i 4}\left(\frac{\partial B_{y}}{\partial \theta}\right)^{2}
\end{array}\right.
$$

それぞれの $k$ は夷䤅值から決定される。 測定值はX軸方向を容易軸方向としているのでこのままで は任意方向の容易軸方向を考慮できない。そのため容易

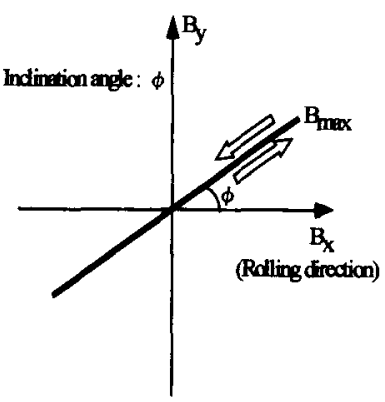

(a) Altemating flux condition

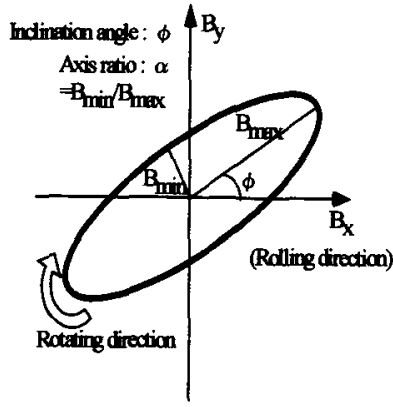

(b) Rotating flux condition
Fig. 2. Representation of alternating and rotating flux.

Hy $(\mathrm{A} / \mathrm{m})$

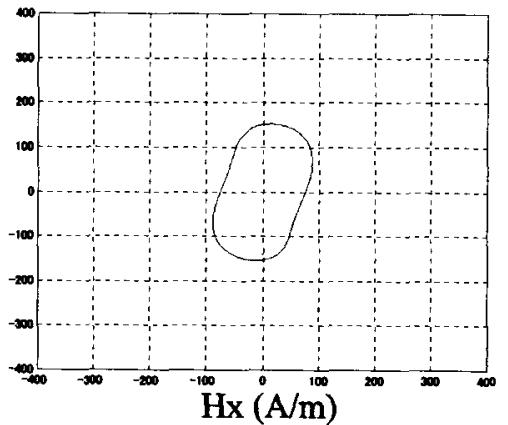

Fig. 3. Magnetic field of the measured result in rotation flux condition

(non-oriented silicon steel sheet, $\alpha=1, \mathrm{~B}_{\max }=1[\mathrm{~T}]$ ).

Hy $(\mathrm{A} / \mathrm{m})$

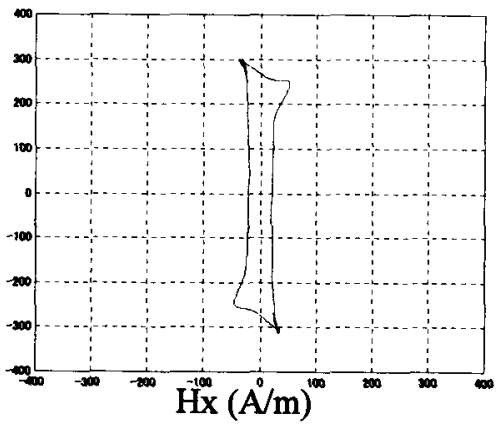

Fig. 4. Magnetic field of the measured result in rotation flux condition

(grain-oriented silicon steel sheet, $\alpha=1, B_{\max }=1[T]$ ).

$\mathrm{Hy}(\mathrm{A} / \mathrm{m})$

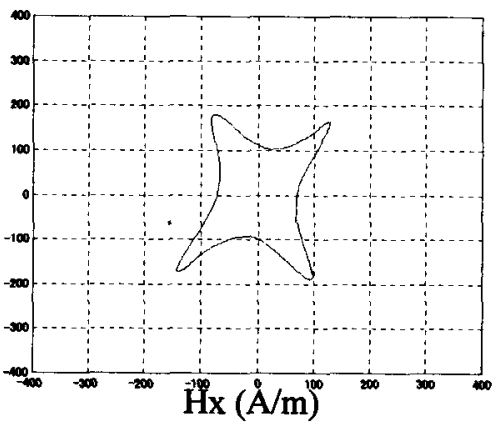

Fig. 5. Magnetic field of the measured result in rotation flux condition

(double grain-oriented silicon sheet, $\alpha=1, \mathrm{~B}_{\max }=1$ [T]). 
軸方向と最大磁束密度方向の角度 $\phi$ を用いて以下のように 表される。

$$
\begin{aligned}
& {\left[\begin{array}{l}
H_{x} \\
H_{y}
\end{array}\right]=\left[\begin{array}{ll}
a_{1} & a_{2} \\
a_{3} & a_{4}
\end{array}\right]\left[\begin{array}{l}
B_{x} \\
B_{y}
\end{array}\right]+\left[\begin{array}{ll}
b_{1} & b_{2} \\
b_{3} & b_{4}
\end{array}\right]\left[\begin{array}{l}
\frac{\partial B_{x}}{\partial \theta} \\
\frac{\partial B_{y}}{\partial \theta}
\end{array}\right]} \\
& \left\{\begin{array}{l}
a_{1}=\cos ^{2}(\phi) v_{x r}+\sin ^{2}(\phi) v_{y r} \\
a_{2}=a_{3}=\sin (\phi) \cos (\phi) v_{x r}-\sin (\phi) \cos (\phi) v_{y r} \\
a_{4}=\sin ^{2}(\phi) v_{x r}+\cos ^{2}(\phi) v_{y r}
\end{array}\right. \\
& \left\{\begin{array}{l}
b_{1}=\cos ^{2}(\phi) v_{x i}+\sin ^{2}(\phi) v_{y i} \\
b_{2}=b_{3}=\sin (\phi) \cos (\phi) v_{x i}-\sin (\phi) \cos (\phi) v_{y i} \\
b_{4}=\sin ^{2}(\phi) v_{x i}+\cos ^{2}(\phi) v_{y i}
\end{array}\right.
\end{aligned}
$$

ここでのこのモデリングを用いて磁界解析を行った。それ ぞれのvは（5）式で求まったものである。

\section{2 数僬解析手法}

ElSモデリングを有限要素法に適用するための定式化を行う。静 磁湯にお计るマクスウェルの電磁方程式は以下のように表せる。

$$
\begin{aligned}
\operatorname{rot} \mathbf{H} & =\mathbf{J}_{\mathbf{0}} \\
\operatorname{div} B & =0
\end{aligned}
$$

ただし、Hは磁界強度でJ、は電流密度、Bは磁束密度である。こ れらの式と（5）式の E⿰冫欠 モデリングを用いて定式化すると最終 的な 2 次元場の支䦿方程式は以下のようになる。

$$
\begin{aligned}
J_{0}+J_{m} & =\frac{\partial}{\partial x}\left(a_{3} \frac{\partial A_{z}}{\partial y}-a_{4} \frac{\partial A_{z}}{\partial x}\right)-\frac{\partial}{\partial y}\left(a_{1} \frac{\partial A_{z}}{\partial y}-a_{2} \frac{\partial A_{z}}{\partial x}\right) \\
& +\frac{\partial}{\partial \theta}\left\{\frac{\partial}{\partial x}\left(b_{3} \frac{\partial A_{z}}{\partial y}-b_{4} \frac{\partial A_{z}}{\partial x}\right)-\frac{\partial}{\partial y}\left(b_{1} \frac{\partial A_{z}}{\partial y}-b_{2} \frac{\partial A_{z}}{\partial x}\right)\right\}
\end{aligned}
$$

(9)

$$
J_{m}=v_{o} \text { rot } \mathbf{M}
$$

ここで、M怺久磁石の磁化である。本解析ではこの支配方程式 をガラーキン法を用いて值接龍散化を行った。

\section{3 跌损侽析}

本解析では磁界强度と磁束密度をべクトル量で表現でき るため鉄損の直接計算が可能である。以下に鉄損を求める 式を示す。

$$
P_{t}=\frac{1}{\rho T} \int_{0}^{T}\left(H_{x} \frac{d B_{x}}{d t}+H_{y} \frac{d B_{y}}{d t}\right) d t
$$

ここで $\rho$ は材料密度、Tは周期である。 全铁員は以下の式て求めた。

$$
P_{t_{\text {tout }}}=\rho \cdot \mathrm{Dp} \cdot \mathrm{Nos} \cdot \sum_{i=1}^{N o s} P t_{i} \cdot S_{i}
$$

ここで、Dpはケイ素銅板の厚み、Nos はケイ素銅板の林数であ る。
Table 1

\begin{tabular}{ccc}
\hline & Model 1 & Model 2 \\
\hline Teeth 1 [deg] & 0 & 28 \\
Teeth $2[\mathrm{deg}]$ & 0 & 119 \\
Teeth $3[\mathrm{deg}]$ & 0 & 89 \\
Teeth $4[\mathrm{deg}]$ & 0 & 59 \\
Teeth $5[\mathrm{deg}]$ & 0 & 88 \\
Teeth 6 [deg] & 0 & 58 \\
Teeth $7[\mathrm{deg}]$ & 0 & 28 \\
Teeth 8 [deg] & 0 & 118 \\
Teeth 9 [deg] & 0 & 89 \\
Teeth $10[\mathrm{deg}]$ & 0 & 120 \\
Teeth $11[\mathrm{deg}]$ & 0 & 88 \\
Teeth $12[\mathrm{deg}]$ & 0 & 118 \\
Total iron loss [W] & 0.43795 & 0.42659 \\
Average of $\mathrm{B}_{\max }$ & $0.5800[\mathrm{~T}]$ & $0.5764[\mathrm{~T}]$ \\
\hline
\end{tabular}

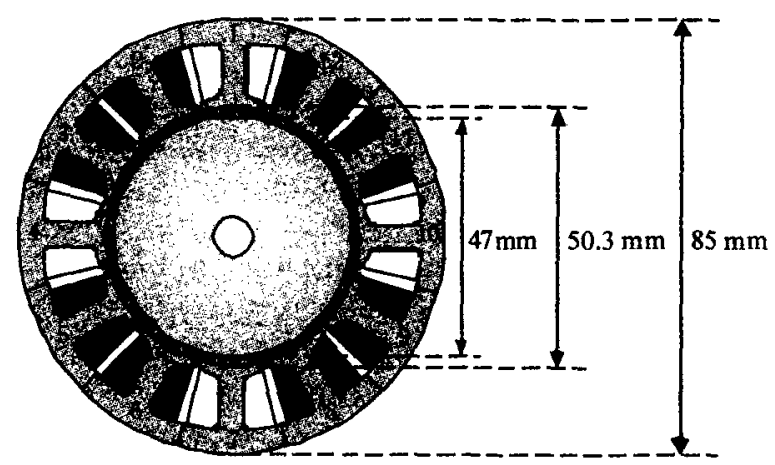

$\mathrm{u} \square \mathrm{v} \square \mathrm{w}$

Fig. 6. Analysis model of the permanent magnet motor

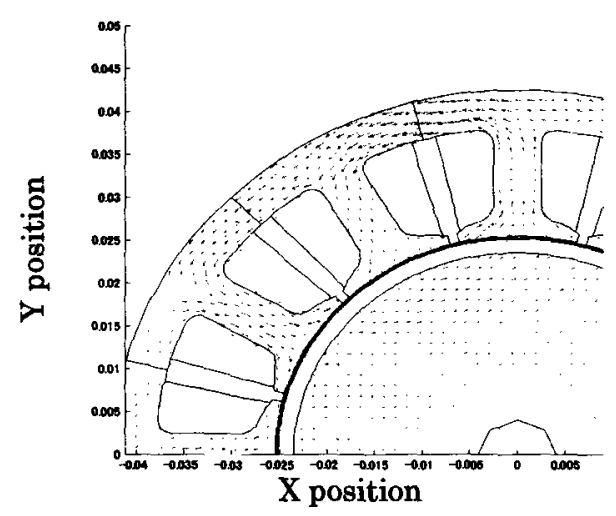

(a) Model 1

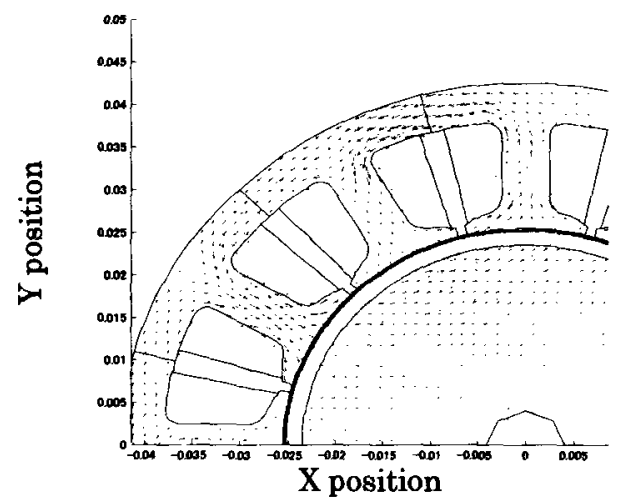

(b) Model 2

Fig. 7. Distribution of the $\mathbf{B}$ and $\mathbf{H}$ vectors. 


\section{4. 解析结果と検封}

Fig. 6 に解析モデルを示す。 3 相励磁なのでU、V、W はそれぞれの相である。図のようにティースが 12 分割さ れた分割コアを用いている。またロータの表面に磁石を配 置している。表 1 にモデル 1 とモデル 2 の詳細を示す。モ デル 1 については従来のモータと同じですべてのティース の容易軸方向が 0 度方向である。モデル 2 につては各テ イースを最大磁束密度方向と容易軸の方向の角度にそれぞ れ重みをつけ最適であると考えられる角度を用いている。 重み係数はそれぞれ実䄼值を参考に設定している。モデル 1 とモデル 2 の容易軸方向以外の条件は同じである。

Fig. 7 は磁界強度と磁束密度のある瞬間のベクトル分布 及びポテンシャル分布である。従来の磁界解析では不可能 であった磁界強度と磁束密度の位相差を表現できているこ とがわかる。また、モデル 1 とモデル 2 では位相差がティ 一ス部で違っていることがわかる。つまり、容易軸方向を 最適化しているモデル 2 では磁界强度べクトルと磁束密度 ベクトルの位相差が小さくなっているといえる。

Fig. 8 は鉄損分布である。従来直接鉄損分布を計算する ことは困難であったが本手法を用いることによって直接計 算が可能となっている。モデル 1 とモデル 2 のティース 2 を比べると最大磁束密度の方向と容易軸方向が同一方向で ある部分はロスが比較的小さく困難軸方向と同一方向に向 いている部分で仕比較的多くなっていることがわかる。ま た、モデル 1 とモデル 2 では鉄損分布が暴なっていること がわかる。しかしながら両者を比べてもはっきりした違い はわからない。表 1 の全鉄損值を見ると、モデル 2 の方が モデル1よりも値が小さくなっているにもかかわらず分布 でははっきりした原因はわからない。そこで、Fig.9のよ うに鉄損を最大磁束密度の二乗で割った。鉄損はおおむる 磁束密度の 2 乗に比例して大きくなるためである。モデル 1 に比べてモデル 2 のティースの付け根部分が小さくなっ ていることがわかる。この部分は回転磁束が発生している 場所で容易軸方向を変えることによって回転磁束が発生し にくくなっていることが鉄損を下げた原因であると考えら れる。

\section{5.まとめ}

本手法を使うことにより鉄損の直接解析が可能となり、 容易軸方向を考虑できることから最適な容易軸方向を計算 し低鉄損化が可能となった。また、磁界強度と磁束密度の 位相差を計算できるため位相差を最小にする形状や材料を 設計できるようになった。

\section{文献}

[1] M.Enokizono and N.Soda, "Iron loss Analysis of Three-Phase Transformer by using Finite Element Method" Proc. ICEE -8, Vol.1, 1998, pp. 852-855.

[2] M.Enokizono and N.Soda, “ New modeling of Vector Magnetic properties for Magnetic Field Analysis" Studies in Applied Electromagnetics and Mechanics, Vol. 13, pp. 418-421.

[3] 祖田直也・榎園正人、“E\&Sモデルによる2 次元磁気特性の ヒステリシスモデリング”、応用磁気学会誌、Vol.24 No.4-2 $2000, \mathrm{p} 827-830$

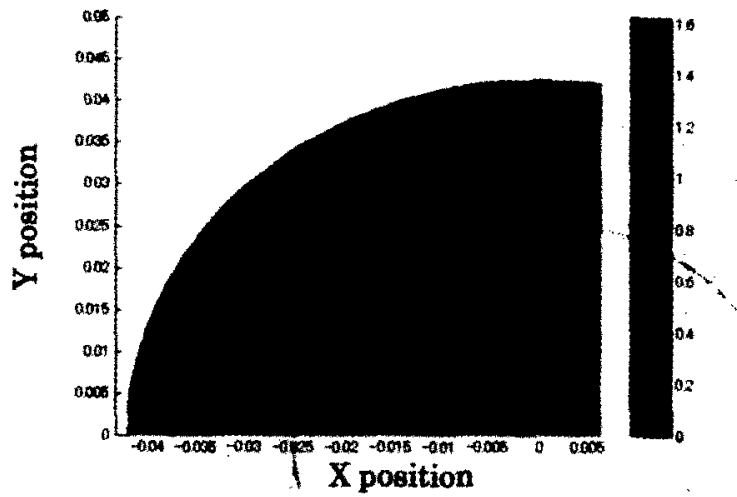

(a) Model 1

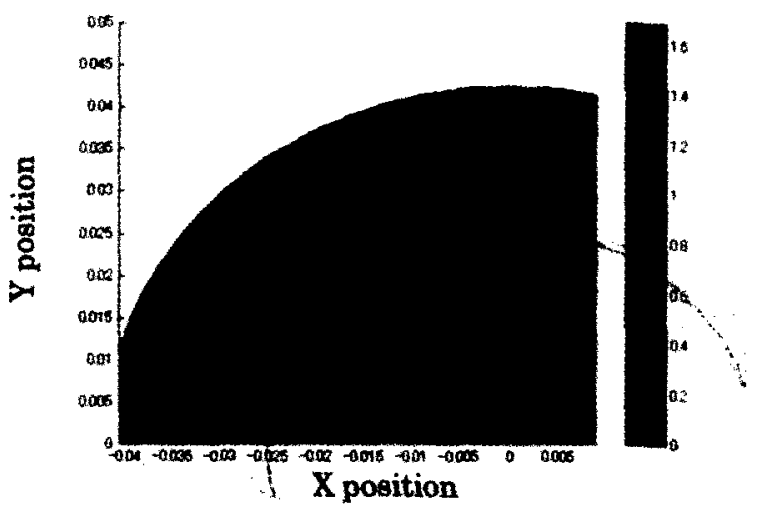

(b) Model 2

Fig. 8. Core loss distribution

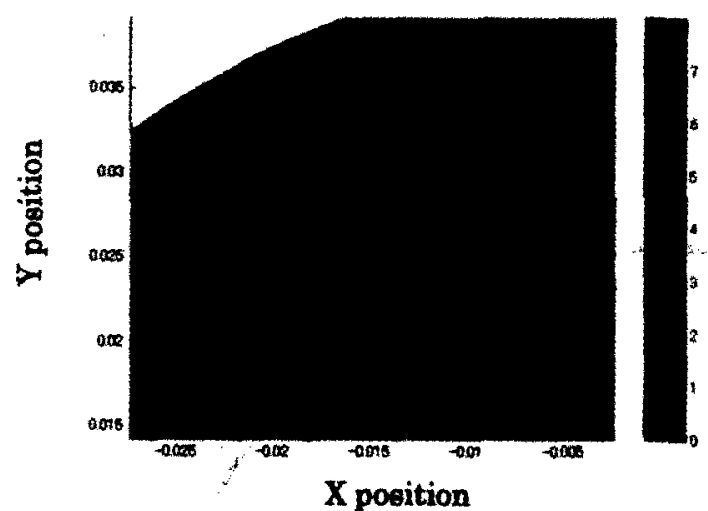

(a) Model 1

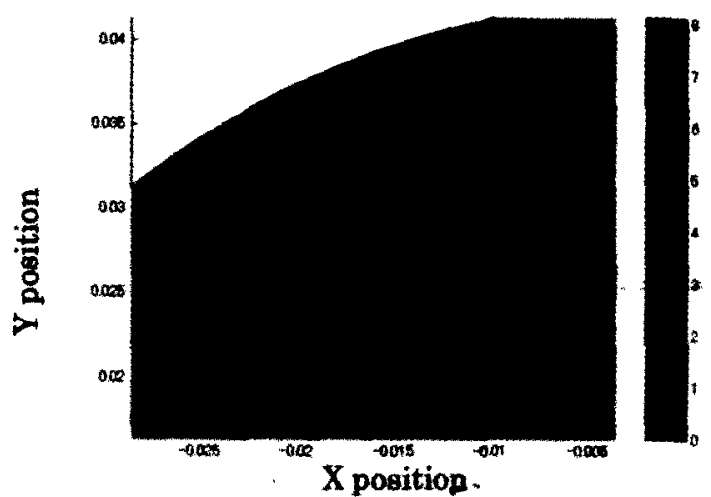

(b) Model 2

Fig. 9. Distribution of the iron loss divided by the square of the magnetic flux density. 